\title{
QUEEN'S
QNEIVERSITY
BELFAST
}

\section{Assessing soil ecosystem processes - biodiversity relationships in a nature reserve in Central Europe}

Caruso, T., Hammer, E. C., Hempel, S., Kohler, J., Morris, E. K., Veresoglou, S. D., Opitz, N., Wehner, J., \& Rillig, M. C. (2018). Assessing soil ecosystem processes - biodiversity relationships in a nature reserve in Central Europe. Plant and Soil. https://doi.org/10.1007/s11104-017-3557-6

\section{Published in:}

Plant and Soil

\section{Document Version:}

Peer reviewed version

Queen's University Belfast - Research Portal:

Link to publication record in Queen's University Belfast Research Portal

\section{Publisher rights}

(C) 2018 Springer International Publishing AG, part of Springer Nature.

This work is made available online in accordance with the publisher's policies. Please refer to any applicable terms of use of the publisher.

\section{General rights}

Copyright for the publications made accessible via the Queen's University Belfast Research Portal is retained by the author(s) and / or other copyright owners and it is a condition of accessing these publications that users recognise and abide by the legal requirements associated with these rights.

Take down policy

The Research Portal is Queen's institutional repository that provides access to Queen's research output. Every effort has been made to ensure that content in the Research Portal does not infringe any person's rights, or applicable UK laws. If you discover content in the Research Portal that you believe breaches copyright or violates any law, please contact openaccess@qub.ac.uk. 
1 Assessing soil ecosystem processes - biodiversity relationships in a nature reserve 2 in Central Europe.

4 Caruso Tancredi ${ }^{* 1,2,3}$, Hammer Edith C. ${ }^{* 1,2,4}$, Hempel Stefan ${ }^{* 1,2}$, Kohler Josef ${ }^{* 1,2}$, Morris E.

5 Kathryn $^{* 1,5}$, Veresoglou Stavros $D^{* 1,2}$, Opitz Nora ${ }^{1,2}$, Wehner Jeannine ${ }^{1,2}$, Rillig Matthias $C^{1,2}$.

$7 \quad{ }^{*}$ These 6 authors contributed equally and are listed alphabetically.

8 Corresponding author Stavros D. Veresoglou Email sveresoglou@,zedat.fu-berlin.de

9

10

${ }^{4}$ Department of Biology, Microbial Ecology/Biodiversity, Lund University, Sölvegatan 37, 22362 Lund, Sweden 
Abstract

Background and aims: Plant diversity - ecosystem processes relationships are essential to our understanding of ecosystem functioning. We aimed at disentangling the nature of such relationships in a mesotrophic grassland that was highly heterogeneous with regards to nutrient availability.

Methods: Rather than targeting primary productivity, like most existing reports do, we focused our study on belowground ecosystem processes. We tested three, largely mutually exclusive, hypotheses of ecosystem processes relationships: the redundancy hypothesis, the insurance hypothesis and the centrifugal model hypothesis. We sampled the grassland twice within a single plant growing season in a spatially explicit way and assayed the soil for nitrification, urease activity, relative bacterial activity and a microbial community profile based on respiration while we simultaneously assessed plant diversity.

Results: Results supported the centrifugal model. We justify the lack of support for the other two hypotheses on the basis of having conducted an observational study in an environmentally heterogeneous site.

Conclusions: The centrifugal model hypothesis appears to be a very good predictive model for explaining diversity in observational, heterogeneous studies. The specific study represents one of the few observational studies that consider measures of ecosystem functioning other than primary productivity. 
The Centrifugal model hypothesis; Diversity-productivity relationships; Ecosystem Functioning; The Insurance Hypothesis; The Redundancy Hypothesis

\section{Introduction}

The relationship between species diversity and ecosystem functioning is highly controversial. The early work from Odum (1953) and Mac Arthur (1955) advocated for increased stability of complex communities, which was later challenged by theoretical work from May (1972) and Pimm (1982). The work of Schulze and Mooney (1993) revived the debate on whether a universal relationship between horizontal diversity (i.e. diversity within a single trophic level) and ecosystem functioning exists, and the possible implications of such a relationship for management and conservation. Understanding the link between the functioning of communities and complexity is a priority for ecologists given the ongoing biodiversity loss (e.g. Chapin III et al. 1997). Currently, there are three theories that address horizontal diversity of terrestrial plants and ecosystem functioning: the redundancy model theory, the insurance hypothesis and the centrifugal organization model (Hooper et al. 2005; Keddy 1990). Most of the literature, however, focuses on the redundancy theory and the insurance hypothesis (Hooper et al. 2005).

The redundancy model theory postulates that increased diversity leads to higher rates of ecosystem processes till a certain threshold, above which there is saturation (Hooper et al. 2005; Reiss et al. 2009). In early studies addressing the redundancy hypothesis, authors tended to use species richness as a measure of diversity but nowadays there is a considerable amount of literature that alternatively utilizes variable forms of functional diversity (Reiss et al. 2009). The extent of the redundancy zone in such a relationship has been questioned with a recent reanalysis 
of seventeen biodiversity experiments, which suggests that there is no functional redundancy among co-occurring plant species (Isbell et al. 2011; Fig. 1a). The absence of a redundancy zone appears to be supported by theoretical work by Yachi and Loreau (1999) who demonstrated that one component of increasing horizontal diversity is a performance-enhancing effect (Yachi and Loreau 1999). In addition, numerous empirical studies have demonstrated a performanceenhancing effect of diversity (e.g. Hector et al. 1999 but see Adler et al. 2011).

The insurance hypothesis on the other hand postulates that increasing diversity has a protective (= insurance) effect against spatial and temporal variability with regards to ecosystem functioning (McNaughton 1977; Yachi and Loreau 1999; Hooper et al. 2005; Fig. 1b). The idea behind the hypothesis is that a number of mechanisms allow a more steady delivery of ecosystem processes over time and space at (McNaughton 1977; Loreau and de Mazancourt 2013). These mechanisms include asynchrony in the responses of different species over time and spatial variability due to abiotic factors but also differences in the speed at which species recover from environmental fluctuations and lower interspecific competition due to functional complementarity (Loreau and de Mazancourt 2013). Models based on the insurance hypothesis therefore predict that when species diversity of a given area is high, pooled measures of ecosystem functioning, over either time or space, result in low standard deviation/variance (across-observations) and vice versa (Fig. 1b). The hypothesis has received both theoretical (Yachi and Loreau 1999; Ives and Hughes 2002) and empirical (e.g. Tilman and Downing 1994; Valone and Hoffman 2003; Tilman et al. 2006) support. The two effects, the increase in stability and the increase in ecosystem process rates, are not necessarily independent; Yachi and Loreau (1999) demonstrated in their theoretical study that identical drivers can result in both an "insurance effect" and an increase in ecosystem process rates. 
The vast majority of the existing literature on the biodiversity - ecosystem functioning (BEF) relationship originates from plot-scale manipulation experiments. Several observational studies that have attempted to test the BEF relationship have not found support for either hypothesis (e.g. Thompson et al. 2005; Adler et al. 2011). This initiated a long debate on the causes of the incongruence in the results between observational and experimental studies (e.g. Thompson et al. 2005; Hector et al. 2007). A reason proposed to explain why no BEF relationship may be detected in observational studies is that in some cases the driving factors of ecosystem processes may be heterogeneity in abiotic variables (Hooper et al. 2005; Hector et al. 2007). Moreover, a confounding factor may be that in experimental studies the diversity gradients generated are on average steeper than those recorded in observational studies (Hector et al. 2007). The mechanisms that drive process rates along strong diversity gradients (e.g. twofold variation) in small homogenous areas may differ from those found in naturally occurring communities where diversity gradients are weak and high environmental heterogeneity exists (e.g. Jiang et al. 2009).

For naturally occurring plant communities, Keddy (1990) proposed the centrifugal organization model (Fig. 1c). The model postulates that within a landscape, more atypical environmental conditions (i.e. the extremes of any environmental axis) may support a higher diversity of plant species. An analog that is often used to explain the centrifugal organization model is that of a core plant community dominating the landscape and multiple rarer communities diverging from the core plant community. In a multidimensional space where multiple environmental gradients coexist it should be expected that the core plant community occurs under average conditions (e.g. pH, moisture) in the landscape. The more the environmental conditions deviate from these "average" conditions the higher the probability of a 
transition of the plant community to a less productive state; the latter happens to be more diverse because of the occurrence of specialist plants (Keddy and MacLellan 1990). Although the original formulation of the model confines its scope to abiotic parameters of the environment, it is possible to relax this assumption and also consider other soil biochemical variables such as extracellular enzyme activities, which is the approach we adopt in this manuscript. If this model is true we expect that plant diversity will be highest in areas where biochemical process rates deviate from the typical - "average" - for the site rates (Fig. 1c). The model is based on and is supported by empirical results (Rosenzweig and Abramsky 1986; Keddy and MacLellan 1990).

What becomes obvious from this brief literature review is that the distinction between cause and effect when assessing the BEF relationship may not always be possible. In experimental studies, when diversity is manipulated within a confined, relatively homogenous space, diversity is clearly the cause of the measured BEF relationship. However, the distinction between cause and effect is not as clear in observational studies. In the case of the centrifugal model it is assumed that the ecosystem processes are those that drive the diversity patterns but this does not preclude a direct effect of plant diversity on ecosystem processes. Another aspect of our literature review worth mentioning is that the vast majority of studies have addressed the BEF relationship using primary productivity as the ecosystem process. To the best of our knowledge the number of studies that have considered other ecosystem processes is very limited (e.g. Kahmen et al. 2005; Kreyling et al. 2008; Vogel et al. 2013). We conducted an observational study in a nature reserve to address the nature of the BEF relationship that was driving plant community dynamics. In our work we adopted a more narrow definition of ecosystem processes than in other studies (e.g. Mace et al. 2011) through excluding "changes in stocks" from the definition found in the abovementioned article; we did so because we expected 
that the "stocks" in such a heterogeneous environment would reflect spatial variability rather than plant diversity mediated effects. Specifically, we targeted two N-cycling processes, urease activity and nitrification and two parameters informative of the microbial community dynamics, community-level physiological profiles (CLPP) and relative bacterial activity. Three of the four targeted ecosystem processes were related to belowground ecosystem functioning: Urease activity and nitrification were ecosystem rates and relative bacterial activity via representing an estimate of the relative abundance of two key group of microbes (i.e. fungi and bacteria) differing considerably in their ecology is a proxy of a number of processes such as nutrient assimilation efficiency and nutrient cycling (which is higher for fungi); sensitivity to disturbance (which is higher for fungi) and ability to recover from perturbations and temporal variability (which is higher for bacteria) (de Boer et al. 2005). CLPP, by contrast, could be viewed as a proxy of decomposition potential. The degree to which CLPP classifies an ecosystem process was less clear than for the other three ecosystem processes. Nevertheless, a high decomposition potential is likely to result in a higher average decomposition rate throughout the growth season because soil receives a constant influx of abiotic compounds such as cellulose rich leaf litter and organic matter rich manure. We thus included CLPP axes as ecosystem processes.

We formulated the following three hypotheses: (i) plant species diversity and ecosystem process rates are positively and linearly correlated (i.e. non-redundant section of a redundancyhypothesis based BEF response); (ii) spatial variability of ecosystem processes is of lower intensity in more diverse plots (insurance hypothesis); (iii) as ecosystem processes deviate from the mean habitat conditions, diversity of each plot will increase (centrifugal model). 
152

153

154

155

156

157

158

159

160

161

162

163

164

165

Materials and methods

\section{Experimental design}

The experimental site is located within the natural reserve of Mallnow $\left(52^{\circ} 27.778^{\prime} \mathrm{N}, 14^{\circ} 29.349^{\prime}\right.$ E), Lebus, $76 \mathrm{~km}$ east of Berlin close to the Polish-German border. The mean annual temperature is $10.35{ }^{\circ} \mathrm{C}$ (mean temperature of the warmest month is $20.25{ }^{\circ} \mathrm{C}$ and of the coldest $0.5{ }^{\circ} \mathrm{C}$ ) and the mean annual precipitation is $546 \mathrm{~mm}$; data are based on mean values for the years $2000-2010$ as these were retrieved from the European Centre for Medium-Range Weather Forecasts (ECMWF) Interim at a resolution of $0.5^{\circ} \times 0.5^{\circ}$. The studied grassland is dominated by Festuca brevipila (aggregate F. ovina) and resembles (with the exception of some alkaline sandy areas) the Festuco-Sedetalia acris plant community (Oberdorfer 2001). The dominant types of soils in the grassland are Luvic Arenosols. Other than occasional grazing, implemented for conservation purposes, disturbance levels in the reserve are low. We focused our harvests on three hills that exhibited gradients in soil texture (the top of the hills were sandy-loamy whereas downhill the soil was sandy - see Horn et al. 2015) with pronounced implications on plant composition and nutrient availability. On each of the three hills we marked three square macroplots with sides that varied from 12 to $15 \mathrm{~m}$. Each square macroplot was divided into smaller square plots. Our work was carried out on the four corner plots in each macroplot, each having a size of $3 \mathrm{x} 3 \mathrm{~m}$; two of them were at the top of the respective hills whereas the other two were at the bottom, i.e. 12 plots in total. This sampling design provided a strong environmental gradient in a small area, with pronounced plant community shifts at a macroplot level that masked any plant community shifts at a landscape level. 
We visited the site on two occasions; the 21 st of May 2012 and the 17th of October 2012.

175 In each of the 12 plots we randomly identified five sets of coordinates that corresponded to our

176 five samples per plot making a total of 60 samples per sampling date. For each of our samples

177 we identified the plant species and the functional group they belonged to (a categorical variable 178 with four levels: either grass, dicotyledonous non-legume, legume, bryophyte/moss) within an 179 area of $12 \mathrm{~cm}$ away from the coordinates and subsequently we obtained two soil cores $(10 \mathrm{~cm}$ 180 depth, $5 \mathrm{~cm}$ diameter) as close to the coordinates of the sample as possible. The soil cores were 181 immediately sieved through a $2 \mathrm{~mm}$ sieve, refrigerated and transferred back to the lab. Soil was 182 stored at $4^{\circ} \mathrm{C}$ till further analysis. Our laboratory analysis included, in addition to assaying 183 multiple abiotic ( $\mathrm{pH}$, total $\mathrm{C}$, total and inorganic $\mathrm{N}$, water content) variables, measuring soil

Data analysis 1988), relative bacterial to fungal activity (Rousk et al. 2009) and community-level physiological profiles (CLPP) of microbes based on consumption of different carbon sources (Campbell et al. 2003. Plant species presence - absence tables were combined into a single plant richness estimate for each individual plot.

The dimensionality of community level physiological profiles (CLPP) was reduced by principal components analysis (PCA). The Kaiser-Guttman and the broken stick criteria agreed in assigning four significant axes. These along with the data on nitrification, urease activity and relative bacterial activity were the seven ecosystem processes (i.e. the four CLPP axes and the three processes) for which we tested hypotheses one and three. 
In order to address the first hypothesis we engaged into three complementary analyses: (i)

mixed effects linear models were fitted separately to each of the ecosystem processes; (ii) the seven ecosystem processes were standardized and averaged and a mixed effects linear model was fitted to the averaged ecosystem process values; (iii) we questioned how many of the ecosystem processes had values over a specific threshold defined as a proportion of the largest observed value (tested all possible integer percentage thresholds - 100 in total). In the literature these three methods can be found with the following names: "the single functions approach", "the averaging approach", "the multiple threshold approach" (Byrnes et al. 2014). For the standardization step in the averaging approach we used $z$-score transformations of ecosystem processes. Our mixed effects linear models in all cases included in addition to the fixed effects factor realized richness, the random effects categorical parameter harvesting occasion and the spatial correlation structure which in our tests minimized AIC values (had the best fit).

To assess the second hypothesis, we implemented the methodology described in Tilman et al. (1998). The analysis was conducted separately for nitrification, urease activity, relative bacterial activity and each of the substrates assayed in CLPP analyses. For each plot and process, we standardized the mean $\bar{x}$ relative to the respective standard deviation of the mean $\sigma$ : $\left(S=\bar{x} f_{\sigma}\right)$. Higher values of $S$ indicate greater stability. To reduce the likelihood of a statistical Type I error we averaged the $S$ values for CLPP, which left us with four separate variables, nitrification, urease activity, relative bacterial activity and CLPP. The relationship between $\mathrm{S}$ and species richness was assessed separately for each variable through a mixed-effects linear model as stated earlier.

To evaluate support for the third hypothesis we conducted a PCA on the seven ecosystem processes that yielded four significant PCA axes. To account for spatial autocorrelation issues 
the PCA was conducted on the residuals of spatial autocorrelation models fitted on individual ecosystem processes. We then calculated the Mahalanobis distances of each sample from the centroid of the cloud of points. Mahalanobis distances represent a unitless measure of distance between points in a multidimensional space (Penny 1996). We subsequently averaged Mahalanobis distances per plot and assessed any potential relationship with plot species richness through a comparable mixed-effects linear model to that described in the earlier paragraph. In this way, we could account for deviation of ecosystem processes from the mean habitat ecosystem functioning conditions.

All analyses were conducted in R v 2.14.2 (R Development Core Team 2012). Data transformations to correct for normality were conducted as appropriate. While addressing the first two hypotheses we used univariate rather than multivariate statistics in assessing the relationship of multiple variables with species richness. We adopted this liberal approach (i.e. an approach that results in a higher likelihood of a type I statistical error - rejecting the null hypothesis in the absence of sufficient evidence - than a type II statistical error - failing to reject the null hypothesis when there is evidence against it) in order to ensure that we would better detect support for either hypothesis. For the same reason we report in our results $p$ values as high as 0.1. Multivariate analyses to pool CLPP and to test hypothesis three were carried out following standardization of the matrices of the dependent variables.

Given the probabilistic nature of statistical analyses, absence of support for a result does not necessarily imply rejection. To this end we aimed at testing our hypotheses in a way that the statistical power would be comparable for all hypotheses. In this respect any positive or negative results would be descriptive of the relative ecological importance of each of the three causes or outcomes of biodiversity. 
Results

At both sampling times a strong plant species richness gradient was observed in plots ranging from 4 to 15 plant species. No differences in plant richness (across samples - the plot richness that is reported earlier was calculated through pooling sample data belonging to the same plot) were found between the two sampling dates, which in May were $4.75 \pm 1.6$ (mean $\pm \mathrm{SE}$ ) plant species and in October $4.38 \pm 1.5$ plant species. The most diverse macroplot was macroplot I (averaging 13.5 and 13 plant species on the two sampling dates), and the least diverse was macroplot II (averaging 7.4 and 5.8 plant species - average on the two sampling dates). The extent of variability in the soil parameters in the experimental site is presented in Table 1. Preliminary testing showed that no biochemical parameter alone could predict plant species richness.

With regards to hypothesis one (redundancy model), the only significant single functions test was that on urease activity data $\left(t_{\text {richness }}=2.17, P=0.032\right)$ with the rest having fits with $P>0.1$ (supplement). The averaging model approach did not yield evidence for the redundancy model either $\left(t_{\text {richness }}=-0.25, P=0.8\right.$ - supplement). The multiple thresholds approach (supplement) yielded significant relationships for only four (out of 100) thresholds, which was attributed to stochasticity. With regards to hypothesis two (insurance hypothesis), we only found weak evidence in support of a positive relationship between plant species richness and $S_{\text {relative bacterial }}$ activity. $\left(P_{\text {species richness }}=0.086, P_{\text {sampling }}=0.003-\right.$ Fig. 3$)$. By contrast, the relationship between mean 
Mahalanobis distances per plot and plant species richness (centrifugal organization model) was significantly positive ( $P=0.046$ - Fig. 4 ).

Discussion

We present here results from an empirical observational study. The grassland where the study was carried out experienced limited human related disturbance and was sustainably managed. Moreover, the focus on a nutrient-limited grassland environment ensured a moderately simple trophic system in which to address our hypotheses; dynamics in simple trophic systems are always easier to explain (e.g. Tetard-Jones et al. 2007). In the introduction we highlighted that part of the novelty of our study was the focus on belowground ecosystem processes. Why is it important to better understand the dynamics of belowground ecosystem processes? Firstly, belowground ecosystem processes have a pronounced effect in regulating the output rates of ecosystem services and goods (Mace et al. 2012). For example, high rates of $\mathrm{N}$ mineralization may indicate a fast turnover of $\mathrm{N}$, increased primary productivity and apparently higher availability of animal fodder (e.g. Fornara and Tilman 2009). Yet, the importance of studying belowground ecosystem processes mainly relates to them representing indicators of ecosystem resilience and sustainability of existing management regimes. For example, Fagotti et al. (2012) were able to demonstrate that conversion of a forest area in Brazil to arable land had pronounced negative effects on all soil N-cycling indicators including nitrification and urease activity rates. Similarly, pronounced variability in microbial community related indices such as relative 
bacterial activity and microrespiration rates may be indicative of disturbance regimes (e.g. Kang and Mills 2004).

We tested two of the most prevalent hypotheses in ecosystem ecology that link species diversity and ecosystem processes, the redundancy hypothesis and the insurance hypothesis. Despite our liberal approach, with the exception of urease activity for the single functions approach and the relative bacterial activity for which some weak evidence for the insurance hypothesis was found, we found no evidence for either of them. We believe that there may be two reasons for this result: (i) because of the strong environmental gradients in our macroplots, ecosystem process rates may have been primarily driven by abiotic factors - this appears to be a recurrent concept of relevant studies in the literature (e.g. Hooper et al. 2005); yet, testing the redundancy hypothesis first in any type of ecosystem is the most intuitive way to initiate exploration of BEF relationships and the number of empirical studies that have supported this idea is extremely limited; (ii) unlike most of the existing literature, we have not addressed plant productivity as a demonstration process of an ecosystem process - potentially the mechanisms that drive the BEF relationship patterns for plant productivity differ from those for the ecosystem processes we studied here. Romanuk and Kolasa (2002) assessed species richness and ecosystem stability relationships in an aquatic system and reported that when environmental variability in the total community was high any BEF relationships were masked; yet, this has been one of the very few empirical studies to confirm the results of theoretical models with regards to the potential impacts of abiotic variability in a system (e.g. Fridley 2001). As a matter of fact, there has been a strong debate that an insurance (portfolio) effect may be expected in environmental data as a result of statistical reasons alone (e.g. Doak et al. 1998). On the other hand, when addressing the redundancy hypothesis, we did not assume any redundancy zone. Other than the 
fact that the existing literature appears to support such an assumption (e.g. Isbell et al. 2011), we justify our choice based on the strong, almost fourfold, plant species richness gradient that was found in our site (4-15 plant species); any potential redundancy effect might have been expected only for the most diverse plant communities and a positive relationship between plant species richness and ecosystem functioning should still have been detectable.

We found support for the hypothesis that plots with more atypical conditions would support higher plant diversity (hypothesis three - Fig 4). Contrary to the other two hypotheses where plant species diversity was a predictor of ecosystem functioning, in the case of the centrifugal model it is assumed that plant species diversity is an outcome of variability in ecosystem processes that is driven by environmental variability. In reality, plant species diversity is both a response and a predictor of ecosystem functioning, which is definitely true in our observational study. The idea behind the centrifugal model is based on the fact that local plant communities are open to plant migration. Areas in the landscape that experience atypical plant growth conditions may be favorable for plant species that typically do not occur in the site. Simultaneously, the migration potential of the plant species dominant in the landscape is high and they can support sink populations in such unfavorable patches (Loreau and Mouquet 1999). The result is that these patches become colonized by more diverse plant communities than the rest of the landscape. Based on this the effect should be more pronounced when there are strong environmental gradients. Our view is that through focusing our study on sites with strong environmental gradients we unintentionally selected for this type of effect. The centrifugal model remains an underexplored hypothesis in ecosystem ecology and our results highlight how important this alternative mechanism may be in explaining community dynamics in natural plant communities. 

than primary productivity (e.g. Romanuk and Kolasa 2002; Mokany et al. 2008). Observational studies typically encounter increased complexity associated with the complexity of natural systems and thus lack the mechanistic resolution of manipulative studies. On the other hand, they represent excellent tests of the extent of ecological significance of identified mechanisms from manipulative experiments - whether they are masked or not from environmental "noise". As stated in the introduction, there has been strong experimental support in the literature for the first two hypotheses we addressed, the redundancy hypothesis and the insurance hypothesis; yet we did not detect any clear evidence for either of them in our study site. Could this have been due to limited statistical power? The number of unique plots was moderately high and the statistical approach we implemented was quite liberal. Definitely, had we analyzed a higher number of samples, many of these slopes would have been significant but this would have been because of subtle changes; the statistical power was sufficient to find significance of the centrifugal model in comparison. As stated earlier we believe that this result was due to the specific environmental variability that characterized our site; due to the specific settings, richness was the effect and not the cause of ecosystem processes variability. Yet, this highlights our ignorance on the amount of environmental variability required to mask any redundancy or insurance effects of plant diversity. A central take home message from our report is that future studies should focus on the level of environmental variability that is required to mask such relationships, rather than on addressing the presence/absence of BEF relationships.

In conclusion, in our report we tested three influential BEF hypotheses with data in a grassland that exhibited high environmental variability. Our analysis allowed us to study how this high environmental variability could affect BEF relationships, and specifically effects on 
belowground ecosystem process rates that have rarely been addressed before. To the best of our knowledge, our report is the first in terrestrial ecosystems to not find support for either the redundancy or the insurance hypothesis. By contrast, we did find support for the centrifugal model. Finally, based on our results we highlighted gaps in the existing BEF relationships literature that have the potential to initiate a new generation of experiments addressing BEF relationships.

\section{Acknowledgments-Contributions}

The project was funded by the Dahlem Center of Plant Sciences. We would like to thank Erik Verbruggen, Stefanie Maaß and Daniel Daphi for technical assistance. Coordinated the project: $\mathrm{SH}$; Acquired funding for the project: TC, ECH, SH, JK, EKM, SDV; conducted the harvests: TC, ECH, SH, JK, EKM, SDV, NO, JW; conceived the analysis, analyzed the data and wrote the paper: SDV; everybody contributed comments to the manuscript.

\section{References}

Adler PB, Seabloom EW, Borer ET, Hillebrand H, Hautier Y, Hector A, Harpole WS, O’Halloran LR, Grace JB, Anderson TM, Bakker JD, Biederman LA, Brown CS, Buckley YM, Calabrese LB, Chu CJ, Cleland EE, Collins SL, Cottingham KL, Crawley MJ, Damschen EI, Davies KF, DeCrappeo NM, Fay PA, Firn J, Frater P, Gasarch EI, Gruner DS, Hagenah N, 
Lambers JHR, Humphries H, Jin VL, Kay AD, Kirkman KP, Klein JA, Knops JMH, La Pierre KJ, Lambrinos JG, Li W, MacDougall AS, McCulley RL, Melbourne BA, Mitchell CE, Moore JL, Morgan JW, Mortensen B, Orrock JL, Prober SM, Pyke DA, Risch AC, Schuetz M, Smith MD, Stevens CJ, Sullivan LL, Wang G, Wragg PD, Wright JP, Yang LH (2011) Productivity is a poor predictor of plant species richness. Science: $333,1750-1753$.

Beck TH (1979) Die Nitrifikation in Böden (Sammelreferat). Jourbal of Plant Nutrition and Soil Science, 142: 299-309.

Byrnes JEK, Gampfeldt L, Isbell F, Lefcheck JS, Griffin JN, Hector A, Cardinale BJ, Hooper DU, Dee LE, Duffy JE (2014) Investigating the relationship between biodiversity and ecosystem multifunctionality: challenges and solutions. Methods Ecol Evol 5:, 111-124.

Campbell CD, Chapman SJ, Cameron CM, Davidson MS, Potts JM (2003) A Rapid Microtiter Plate Method To Measure Carbon Dioxide Evolved from Carbon Substrate Amendments so as To Determine the Physiological Profiles of Soil Microbial Communities by Using Whole Soil. Appl Environ Microbiol, 69: 3593-3599.

Chapin III FS, Walker BH, Hobbs RJ, Hooper DU, Lawton JH, Sala OE, Tilman D (1997) Biotic control over the functioning of ecosystems. Science, 277: 500-504.

de Boer W, Folman LB, Summerbell RC, Boddy L, (2005) Living in a fungal world: impact of fungi on soil bacterial niche development. FEMS Microbiol Rev 29: 795e811.

Doak DF, Bigger D, Harding EK, Marvier MA, O'Malley RE. Thomson D (1998) The statistical inevitability of stability-diversity relationships in community ecology. Am Nat, 151: 264-276. 
Fagotti DSL, Miyauchi MYH, Oliveira AG, Santinoni IA, Eberhardt DN, Nimtz A, Ribeiro RA, Paula AM, Queiroz CAS, Andrade G, Zangaro W, Nogueira MA (2012) Gradients in N-cycling attributes along forestry and agricultural land-use systems are indicative of soil capacity for $\mathrm{N}$ supply. Soil Use Manage, 28: 292-298.

Fornara DA, Tilman D (2009) Ecological mechanisms associated with the positive diversityproductivity relationship in an N-limited grassland. Ecology 90: 408-418.

Fridley JD. (2001) The influence of species diversity on ecosystem productivity: how, where and why? Oikos 93: 514-526.

Hector A, Schmid B, Beierkuhnlein C, Caldeira MC, Diemer M, Dimitrakopoulos PG, Finn JA, Freitas H, Giller PS, Good J, Harris R, Hogberg P, Huss-Danell K, Joshi J, Jumpponen A, Korner C, Leadley PW, Loreau M, Minns A, Mulder CPH, O’Donovan G, Otway SJ, Pereira JS, Prinz A, Read DJ, Scherer-Lorenzen M, Schulze ED, Siamantziouras ASD, Spehn EM, Terry AC, Troumbis AY, Woodward FI, Yachi S, Lawton JH (1999) Plant diversity and productivity experiments in European grasslands. Science 286: 1123-1127.

Hector A, Joshi J, Scherer-Lorenzen M, Schmid B, Spehn EM, Wacker L, Weilenmann M, Bazeley-White E, Beierkuhnlein C, Caldeira MC, Dimitrakopoulos PG, Finn JA, Huss-Danell K, Jumpponen A, Leadley PW Loreau M, Mulder CPH, Neßhöver C, Palmborg C, Read DJ, Siamantziouras SD, Terry AC, Troumbis AY (2007) Biodiversity and ecosystem functioning: reconciling the results of experimental and observational studies. Funct Ecol 21: 998-1002.

Hooper DU, Chapin III FS, Ewel JJ, Hector A, Inchausti P, Lavorel S, Lawton JH, Lawton JH, Lodge DM, Loreau M, Naeem S, Schmid B, Setälä H, Symstad AJ, Vendermeer J, Wardle DA 
(2005) Effects of biodiversity on ecosystem functioning: a consensus of current knowledge. Ecol Monogr 75: 3-35.

Horn S, Hempel S, Ristow M, Rillig MC, Kowarik I, Caruso T. (2015) Plant community assembly at small scales: spatial versus environmental factors in a central European grassland. Acta Oecol 63: 56-62.

Isbell F, Calcagno V, Hector A, Connolly J, Stanley Harpole W, Reich PB, Scherer-Lorenzen M, Schmid B, Tilman D, van Ruijven J, Weigelt A, Wilsey BJ, Zavaleta ES, Loreau M (2011) High plant diversity is needed to maintain ecosystem services. Nature 477: 199-196.

Ives AR, Hughes JB (2002) General relationships between species diversity and stability in competitive systems. Am Nat 159: 388-395.

Jiang L, Wan SQ, Li LH (2009). Species diversity and productivity: Why do results of diversitymanipulation experiments differ from natural patterns? J Ecol, 97: 603-608.

Kahmen A, Perner J, Andorff V, Weisser W, Buchmann N (2005) Effects of plant diversity, community composition and environmental parameters in montane European grasslands. Oecologia 142: 605-615.

Kandeler E, Gerber H (1988) Short-term assay of soil urease activity using colorimetric determination of ammonium. Biol Fertil Soils 6: 68-72.

Kang SH, Mills AL (2004) Soil bacterial community structure changes following disturbance of the overlying plant community. Soil Sci 169: 55-65. 
434

435

436

437

438

439

440

441

442

443

444

445

446

447

448

449

450

451

452

453

Keddy PA (1990) Competitive hierarchies and centrifugal organization in plant communities. In:

J. Grace J, Tilman D, (Eds) Perspectives on plant competition. San Diego: Academic Press, 266290.

Keddy PA, MacLellan P (1990) Centrifugal organization in forests. Oikos, 59: 75-84.

Kreyling J, Beierkuhnlein C, Ellis L, Jentsch A (2008) Invasibility of grassland and heath communities exposed to extreme weather events - additive effects of diversity resistance and fluctuating physical environment. Oikos 117: 1542-4554.

Loreau M, de Mazancourt C (2013) Biodiversity and ecosystem stability: a synthesis of underlying mechanisms. Ecol Lett 16: 106-115.

Loreau M, Mouquet N (1999) Immigration and maintainance of local species diversity. The Am Nat 154: 427-440.

MacArthur RH (1955) Fluctuations of animal populations and a measure of community stability. Ecology 36: 533-535.

Mace GM, Norris K, Fitter AH (2011) Biodiversity and ecosystem services: a multilayered relationship. Trends Ecol Evol 27: 19-26.

May RM (1972) Will a large complex system be stable? Nature 238: 413-414.

McNaughton SJ (1977) Diversity and stability of ecological communities - comment on role of empirism in ecology. Am Nat 111: 515-525.

Mokany K, Asj J, Roxburgh S (2008) Functional identity is more important than diversity in influencing ecosystem processes in a temperate native grassland. J Ecol 96: 884-893. 
Oberdorfer EP (2001) Pflanzensoziologische Exkursionsflora für Deutschland und angrenzende Gebiete. 8th ed.., Stuttgart, Ulmer.

Odum EP (1953) Fundamentals of ecology Philadelphia, W. B. Saunders.

Penny KI (1996) Appropriate critical values when testing for a single multivariate outlier by using the Mahalanobis distance. App Stat 45: 73-81.

Pimm SL (1982) Food webs. London, Chapman \& Hall.

Pinheiro J, Bates D, DebRoy S, Sarkar D, R Development Core Team (2013). nlme: Linear and Nonlinear Mixed Effects Models. R package version 3.1-108.

R Development Core Team (2012) R: a language and environment for statistical computing. R Foundation for Statistical Computing, Vienna

Reiss J, Bridle JR, Montoya JM, Woodward G (2009) Emerging horizons in biodiversity and ecosystem functioning research. Trends Ecol Evol 24: 505-514.

Romanuk TN, Kolasa J (2002) Environmental variability alters the relationship between richness and variability of community abundances in aquatic rock pool microcosms'. Ecoscience, 9: 5562.

Rosenzweig ML, Abramsky Z (1986) Centrifugal community organization. Oikos, 46: 339-348.

Rousk J, Brookes PC, Baath E (2009) Contrasting Soil pH Effects on Fungal and Bacterial Growth Suggest Functional Redundancy in Carbon Mineralization. Applied and Environmental Microbiology 75: 1589-1596.

Schulze ED, Mooney HA (1993) Biodiversity and ecosystem function. Berlin, Springer-Verlag. 
474 Tetard-Jones C, Kertesz MA, Gallois P, Preziosi RF (2007) Genotype-by-genotype interactions 475 modified by a third species in a plant-insect system. Am Nat: 170, 492-499.

476 Thompson K, Askew AP, Grime JP, Dunnett NP, Willis AJ (2005) Biodiversity, ecosystem 477 function and plant traits in mature and immature plant communities. Funct Ecol 19: 355-358.

478 Tilman D, Lehman CL, Bristow CE (1998) Diversity-stability relationships: Statistical 479 inevitability or ecological consequence? Am Nat 151: 277-282.

480

481

48 483

484

485

486

487

488

489

490

491

492

Tilman D, Reich PB, Knops JMH (2006) Biodiversity and ecosystem stability in a decade-long grassland experiment. Nature 441: 629-632.

Tilman D, van Ruijven J, Weigelt A, Wilsey BJ, Zavaleta ES, Loreau M (2011) High plant diversity is needed to maintain ecosystem services. Nature 477: 199-202.

Valone TJ, Hoffman CD (2003) Population stability is higher in more diverse annual plant communities. Ecol Lett 6: 90-95.

Vogel A, Eisenhauer N, Weigelt A, Scherer-Lorenzen,M (2013) Plant diversity does not buffer drought effects on early-stage litter mass loss rates and microbial properties. Glob Change Biol 19: $2795-2803$.

Yachi S, Loreau M (1999) Biodiversity and ecosystem productivity in a fluctuating environment: The insurance hypothesis. Proc Natl Acad Sci U.S.A 96: 1463-1468. 
Table 1. Variability of indicative soil related environmental parameters assayed in the sampling site over the course of the experiment. All parameters were assayed separately in the two sampling dates. Cumulative results of both sampling dates are presented here.

\begin{tabular}{|c|c|c|c|c|c|}
\hline Variable & Minimum & $25 \%$ quartile & Median & 75\% Quartile & Maximum \\
\hline Total C (\%) & 0.18 & 0.88 & 1.24 & 1.95 & 3.96 \\
\hline Total N (g/kg) & 0.15 & 0.63 & 0.93 & 1.45 & 3.04 \\
\hline Inorganic $\mathrm{N}$ (mg/kg) & 2.30 & 6.27 & 6.92 & 7.64 & 10.43 \\
\hline $\mathrm{pH}$ & 4.73 & 5.86 & 6.80 & 7.90 & 8.42 \\
\hline Urease activity & 1.08 & 4.45 & 8.85 & 18.49 & 48.64 \\
\hline \multicolumn{6}{|l|}{$(\mu \mathrm{g} \mathrm{NH} / \mathrm{g} / \mathrm{h})$} \\
\hline Nitrification (mg & 0.00 & 0.86 & 3.31 & 6.87 & 11.89 \\
\hline \multicolumn{6}{|l|}{$\mathrm{N} / \mathrm{kg} /$ day) } \\
\hline Relative bacterial & 4550 & 18910 & 29880 & 42970 & 184000 \\
\hline \multicolumn{6}{|l|}{ activity (pmol H } \\
\hline Leucin $\left.h^{-1} g^{-1} f w\right)$ & & & & & \\
\hline
\end{tabular}

494

495 


\section{Legends to figures}

Fig. 1. Conceptual figure that highlights the expected relationships between species richness and ecosystem processes rates under (a) the redundancy model (note that in our redundancy model we assume no redundancy zone); (b) the insurance hypothesis; (c) the centrifugal organization model. The darker the color of the rectangles on the left, the higher the hypothesized rates of ecosystem processes are. These are summarized in the figures on the center. The three right panels are descriptive of the ideal results that would provide support to the hypothesis, as these were carried out in our analyses.

Fig. 2. Plant species richness ( $x$ axis)- average ecosystem process rates ( $y$ axis). To average ecosystem process rates, we used a $z$-transformation. Black crosses originate from the first sampling whereas grey crosses from the second. Relationships were assessed through a mixed effects linear model that accounted for temporal and spatial dependences; Note that we did not detect any significant relationship.

Fig. 3. Plant species richness ( $x$ axes) - ecosystem process stability relationships ( $y$ axes). Black crosses originate from the first sampling whereas grey crosses from the second. Relationships were assessed through a mixed effects linear model that accounted for temporal dependence; sampling was used as a fixed effects categorical factor whereas plot was a random effects categorical factor. The letter $S$ is used to denote the ratio between the mean ecosystem processes recorded in the plot standardized based on the respective standard deviation. Note that we only found weak evidence for a positive relationship for relative bacterial activity (panel c, 
$519 P_{\text {richness }}=0.09$ ); in the model the lines for the two sampling dates are drawn separately as there 520 was a significant sampling time effect $(P=0.003)$.

522 Fig. 4. Plant species richness ( $y$ axis) - mean Mahalanobis distance relationship per plot ( $x$ axis)

523 relationship. Black crosses originate from the first sampling whereas grey crosses from the 524 second. The relationship was assessed through a mixed effects linear model that accounted for 525 temporal dependence; sampling time was used as a fixed effects categorical factor whereas plot 526 was a random effects categorical factor. Overlaid black line depicts the significant $(\mathrm{P}<0.05)$ 527 mean Mahalanobis distance effect in explaining plant species richness. Note that analyzing each 528 of these two sampling points separately would yield a steeper slope and it might be the case that 529 through our combined analysis we underestimate the associated effect size. 